effective nor predictable, ${ }^{6}$ any additional method of reducing absorption of ingested poison deserves consideration.

The adsorbent properties of charcoal were described in 1791 by Lowitz, and this knowledge was enthusiastically propounded about 1830 by Touery, a French pharmacist. When his theories were questioned he demonstrated his faith in them in a manner unlikely to be followed by modern clinicians. At a meeting in the French Academy he swallowed several times the lethal dose of strychnine, together with 15 $\mathrm{g}$ of charcoal. He remained unaffected by this heroic experiment, yet it did not impress the medical profession. ${ }^{7}$ Charcoal was then only occasionally used until it was introduced into practice by Lichtwitz in 1908. After a short period of popularity it again fell into disuse. L. E. Holt and P. H. Holz in $1963^{8}$ re-emphasized the merits of activated charcoal, and it then became more frequently used in America, especially for children. In our correspondence columns this week Drs. J. Crammer and B. Davies advocate using it in the treatment of poisoning by tricyclic antidepressant drugs. Activated charcoal is usually prepared from destructive distillation of wood pulp, and it is then treated to increase its adsorptive properties. It should be stored tightly sealed in glass or metal containers. ${ }^{9}$ The best activated charcoal has small particle size, large total surface area, and low mineral content. By these criteria burnt toast, so often recommended, has virtually no adsorptive properties.

Since much of the suggested efficacy of activated charcoal in man derives from isolated instances of poisoning inadequately studied, it should be stressed that its adsorptive capacity for many toxic substances remains uncertain. It probably has little effect in reducing absorption of ethanol, methanol, ferrous sulphate, cyanide, caustic alkalies, and mineral acids. ${ }^{9}$ But reliable animal experiments have shown that it effectively adsorbs salicylate, barbiturate, chlorpromazine, ethchlorvynol, glutethimide, propoxyphene, and kerosene $^{8-10}$ As it will inactivate ipecacuanha, apomorphine by injection is necessary if emesis is also desired.

Activated charcoal reduces gastrointestinal abcorption of salicylate in man, 1112 though salicylate adsorption is reversible to a slight but important extent. ${ }^{12} \mathrm{~W}$. J. Decker and D. G. Corby ${ }^{13}$ advocate that the combination of activated charcoal and apomorphine is even more effective in inhibiting absorption of salicylate.

The dose of charcoal is important. An amount not less than five times the estimated weight of the poison believed to have been ingested should be given. ${ }^{9}$ Larger doses, up to ten times, are required if food is in the stomach. ${ }^{11}$ Since delay in administration decreases its effectiveness, it should if possible be given within 30 minutes of ingestion of the poison. However, especially if delayed-release tablets have been taken in overdose, the charcoal will be effective even after several hours. Its place is therefore more in the home than in the hospital. ${ }^{8}$ Only in poisoning by substances which are likely to have an enterohepatic circulation is repeated administration of charcoal advocated.9

W. E. Calvert and his associates ${ }^{14}$ report that despite the black sludge-like appearance of the charcoal in water, $86 \%$ of children will accept the drink when offered it in a positive, firm, expectant manner. In the unconscious patient charcoal is given by stomach tube after gastric lavage. A practical disadvantage is the black staining of sheets and clothes if the patient vomits.

Despite there being no known contraindication to its use and no inherent toxicity, the adsorptive capacity of activated charcoal in man has been proved for very few poisons. Indiscriminate use is to be discouraged, but it has a place as a first-aid measure in the home and in the hospital for those poisons for which it has been shown to be effective in man or in animal experiments.

1 Corby, D. G., Lisciandro, R. C., Lehman, R. M., and Decker, W. J., Pediatrics, 1967, 40, 871 .

2 Boxer, L., Anderson, F. P., and Rowe, D. S., fournal of Pediatrics, 1969, 74,800 .

3 Matthew, H., British Medical fournal, 1971, 1, 519.

Reid, D. H. S., Archives of Disease in Childhood, 1970, 45, 428.

5 Goulding, R., British fournal of Hospital Medicine, 1971, 5, 858. Corby, D. G., Fiser, R. H., and Decker, W. J., Pediatric Clinics of North America, 1970, 17, 545.

7 Andersen, A. H., Acta Pharmacologica et Toxicologica, 1946, 2, 69.

8 Holt, L. E., and Holz, P. H., Fournal of Pediatrics, 1963, 63, 306.

- Picchioni, A. L., Pediatric Clinics of North America, 1970, 17,535

10 Fiser, R. H., Maetz, H. M., Treuting, J. J., and Decker, W. J., fournal of Pediatrics, 1971, 78, 1045.

11 Decker, W. J., Shpall, R. A., Corby, D. G., Combs, H. F., and Payne, C. E., Clinical Pharmacology and Therapeutics, 1969, 10, 710 .

12 Levy, G., and Tsuchiya, T., Clinical Pharmacology and Therapeutics, 1972 13,317 .

13 Decker, W. J., and Corby, D. G., Clinical Toxicology, 1970, 3, 1.

14 Calvert, W. E., Herbertson, L. M., Corby, D. G., and Decker, W. J., fournal of American Medical Association, 1971, 215, 641

\section{Bovine Tuberculosis}

Perhaps the greatest public health achievement of this century in Britain has been the eradication of bovine tuberculosis. Credit for the suggestion, made over 60 years ago, that it should be attempted must be given to some West of England farmers, and credit for carrying out this immense task to the veterinary profession. Among children enlarged glands in the neck and disease of bones and joints, recently so common, are now rarely seen except in Asian and African immigrants. ${ }^{1}$ In addition to the elimination of bovine tuberculosis there is the mundane advantage that supplies of good meat for human food are increased because carcases do not have to be rejected so often.

The original eradication campaign was interrupted by the second world war, after which a fresh start had to be made. The general plan was to render circumscribed areas free from bovine disease (Eradication Areas) and then gradually to expand them until the whole of the United Kingdom had been covered. Once an area was declared clear cattle, designated attested, could be moved in and out only under licence, but when the whole country became clear these licences became unnecessary. The Tuberculosis Order of 1964 now in force lays down measures for dealing with clinical tuberculosis in cattle and reactors to the tuberculin test. It also $\curvearrowright$ requires all bovines in the country to be suitably marked. This makes tracing sources of infection less difficult.

A tuberculous animal spreads its infection by uterine dis- $\bar{N}$ charge, droppings, respiratory excretions, and in milk. In- N fected milk has always been the chief cause of human disease, but cowmen and others have contracted pulmonary 0 infections simply from their close contact with animals having open lesions of some kind, usually in the lungs. What is of increasing importance is that cows for their part can acquire infection from open cases of human pulmonary tuberculosis. On more than one occasion a mysterious breakdown in the attested state of a herd has been traced to a cowman with recent or relapsed pulmonary disease.

Whatever has now been achieved in cattle, it is well to remember that tuberculosis is a disease which can occur in most mammals, which thus provide a reservoir of infection. Unfortunately the real extent of such infections is unknown, but much is known about tuberculosis in farm livestock besides cattle. That is why it has always been considered wise to keep pigs away from attested stock. In fact most owners 
of pedigree herds make sure that any pigs about the place are free from tuberculosis. Sheep for some unknown reason are remarkably free from it. Apart from harbouring parasitic worms, the cats and dogs on a farm are usually healthy, though like most other mammals these animals anywhere can be infected with tubercle if in contact with it.

Unless there is some special reason, now that cattle as a whole are free from tuberculosis the usual practice is to test annually, or at two-year intervals if the local health position is good. Happily the number of reactors remains very small out of a total cattle population of nine millions. When any reactors are discovered, all ordinary causes are fully investigated by the Ministry of Agriculture veterinary staff. A common trouble stems from animals with longstanding, but not necessarily severe, disease in which foci of potentially pathogenic bacilli have become completely encysted. Lesions may remain in this state for the whole of an animal's life and may be noticed only when it is eventually slaughtered. Some beasts in this state completely lose their cutaneous tuberculin test reactions. Owing to some unfavourable condition of life, or even calving stress, occult foci of infection can break down and active disease become re-established, with serious results. Difficulties sometimes arise about the correct interpretation of reaction to infections with acid-fast bacilli not generally regarded as pathogenic. ${ }^{2}$ But better the slaughter of an occasional animal with a false-positive test than that the public health should suffer from a missed reactor.

If no ordinary cause can be found for the emergence of reactors on a farm, unusual possibilities have to be considered. This is when wild mammals become suspect. Recently in a few counties some pockets of infection have appeared which have defied explanation, and the most likely cause would seem to be a local spontaneous outbreak of disease in wild life. Even badgers have thus come under suspicion in one county. These animals are known to be particularly healthy, probably because of their standards of personal and domestic hygiene, and this is the first occasion when active tuberculosis has been demonstrated in some carcasses and droppings. The matter is being fully investigated by the Ministry of Agriculture. The question will have to be answered whether both cattle and badgers have become infected from a common source, such as rats or possibly a contaminated stream. Chance observations of this sort, of which the significance is not clear, provide no justification for the wholesale slaughter of these or other wild animals.

1 British Medical fournal, 1971, 2, 419.

2 Thrower, W. R., Fournal of the Royal College of Physicians, 1970, 4, 277.

\section{Inappropriate Secretion of ADH}

The syndrome of inappropriate secretion of antidiuretic hormone was first described in a patient with bronchial carcinoma. ${ }^{1}$ It has now been found in many other conditions, which apparently have few clinical features in common. Other diseases of the lung such as tuberculosis and pneumonia may give rise to it. ${ }^{2} \mathrm{~A}$ recent report from the Mayo $\mathrm{Clinic}^{3}$ describes three patients, one with staphylococcal pneumonia and two with viral pneumonia, who showed the typical features. Disorders of the nervous system, such as head injuries, cere- bral tumours, and brain abscesses, gastrointestinal lesions such as tumours of the small intestine and pancreas, all may cause a clinical picture suggestive of secretion of antidiuretic hormone. The syndrome has also been described in patients with myxoedema and acute porphyria and after cardiac bypass. ${ }^{4}$

The pathogenesis of inappropriate secretion of antidiuretic hormone in all these conditions is obscure. Some tumours produce antidiuretic hormone themselves, and the same has been shown to be true of tuberculous lung tissue 5 in one patient. Under physiological conditions the stimulus to secretion of the hormone is thought to be, firstly, changes in the volume of intravascular fluid 6 and, secondly, changes in osmolality of extracellular fluid. ${ }^{7}$ In animals it has been shown that inflation of a balloon within the left atrium results in an increase in rate of urine flow, whereas factors promoting pooling of blood within the periphery, and thus decreasing left atrial pressure, promote increased antidiuretic hormone activity and a decrease in the volume of urine. ${ }^{8}$ In man this association between left atrial pressure and secretion of the hormones is inferential. It has been suggested that in patients with pneumonia a decrease in cardiac output and acute hypoxia may lead to pulmonary vasoconstriction and thus decreased filling of the left atrium. ${ }^{3}$ It is also possible, though perhaps less likely, that infected lung tissue produces a substance resembling the antidiuretic hormone.

Whatever the cause, an oversecretion of the hormone leads to the retention of water, with resulting hyponatraemia. To protect the body against increases in fluid volume, increasing amounts of sodium are lost in urine, but this leads only to further decreases in the osmolality of the body fluids. Thus the increased urinary excretion of sodium is not due to any intrinsic defect in renal tubular function, since the sodium-retaining response to mineralocorticoids in these patients is intact. 9

Certain biochemical abnormalities give the clues to this syndrome, and they were present in the three patients described from the Mayo Clinic. They are, firstly, a fall in the concentration of serum sodium, resulting in a low serum osmolality; and, secondly, an increased urinary excretion of sodium resulting in urine which is hypertonic to plasma. The concenrtation of antidiuretic hormone in the plasma is difficult to assay, but it was raised in one of the Mayo clinic patients.

The clinical features of the syndrome can be considered under two headings. Firstly, there are the signs of the underlying disease; secondly, there are the symptoms of hyponatraemia. When the serum sodium falls to approximately $125 \mathrm{mEq} / \mathrm{L}$., the patient may have some non-specific symptoms-namely, anorexia, nausea, and vomiting. When the concentration falls below $115 \mathrm{mEq} / \mathrm{L}$. the patient becomes progressively excited, depressed, lethargic, and finally comatose. Generalized convulsions may be seen as a terminal event. Those patients with inappropriate secretion of antidiuretic hormone differ from patients with "true" sodium depletion in that such signs of fluid depletion as hypotension, uraemia, and poor skin tone are absent. They can also be distinguished from patients with hyponatraemia due to congestive heart failure or cirrhosis of the liver, who are oedematous, while the patients described here are not. The greatest differential diagnostic problem is the patient with adrenal insufficiency whose ability to excrete water is more impaired than his disorder of sodium metabolism. Thus hyponatraemia without hypotension occurs; only the appropriate tests of endocrine function will differentiate these two conditions. 